\title{
Tribological Behavior of Laser Textured Hot Stamping Dies
}

\author{
Andre Shihomatsu, ${ }^{1}$ Sergio Tonini Button, ${ }^{1}$ and Iris Bento da Silva ${ }^{2}$ \\ ${ }^{1}$ Department of Manufacturing and Materials Engineering, School of Mechanical Engineering, University of Campinas, \\ 13083-970 Campinas, SP, Brazil \\ ${ }^{2}$ Department of Mechanical Engineering, School of Engineering of Sao Carlos, University of Sao Paulo, 13566-590 Sao Carlos, SP, Brazil
}

Correspondence should be addressed to Sergio Tonini Button; sergiol@fem.unicamp.br

Received 30 November 2015; Accepted 6 March 2016

Academic Editor: Patrick De Baets

Copyright (C) 2016 Andre Shihomatsu et al. This is an open access article distributed under the Creative Commons Attribution License, which permits unrestricted use, distribution, and reproduction in any medium, provided the original work is properly cited.

\begin{abstract}
Hot stamping of high strength steels has been continuously developed in the automotive industry to improve mechanical properties and surface quality of stamped components. One of the main challenges faced by researchers and technicians is to improve stamping dies lifetime by reducing the wear caused by high pressures and temperatures present during the process. This paper analyzes the laser texturing of hot stamping dies and discusses how different surfaces textures influence the lubrication and wear mechanisms. To this purpose, experimental tests and numerical simulation were carried out to define the die region to be texturized and to characterize the textured surface topography before and after hot stamping tests with a 3D surface profilometer and scanning electron microscopy. Results showed that laser texturing influences the lubrication at the interface die-hot sheet and improves die lifetime. In this work, the best texture presented dimples with the highest diameter, depth, and spacing, with the surface topography and dimples morphology practically preserved after the hot stamping tests.
\end{abstract}

\section{Introduction}

In recent years, researches on tribology of metal forming processes for the automotive industry are focused on the improvement of products surface quality and process performance. In hot stamping the improvement of the die lifetime is a relevant factor for obtaining better products, lower costs, and high productivity, so it is essential to understand how the severe conditions of pressure and temperature influence the lubrication at the interface dies-sheet and, consequently, the wear mechanisms which can cause die lifetime reduction.

Hot stamping of hardenable steels consists in heating the blank above the austenitizing temperature and then transferring it to the press where it is stamped and finally cooled and tempered between the dies, improving productivity and the mechanical properties of the stamped part like ultimate strength and impact toughness [1].

Hot stamping is a relatively fast process if compared to other metal forming processes, so the manufacturing costs would be significantly increased if production has to be interrupted to premature and frequent changes of worn dies. To resist the severe working conditions of hot stamping, dies must present high hot hardness to minimize wear at high temperatures, low sensitivity to cracks caused by thermal shocks, low sensitivity to local tempering and softening, high mechanical strength to avoid mechanically induced cracks, low chemical affinity with the sheet alloy being stamped, and high oxidation resistance at high temperatures to avoid cracking by corrosion [2].

Therefore, many researches have been presented to improve dies lifetime by developing new materials for dies and blanks and coatings for the steel sheets [3-5].

The wear mechanisms at the tools-workpiece interface are very complicated and therefore have been studied for years by many researchers for several hot metal forming processes. Among the factors which may influence the way die surfaces can be damaged, the most studied are the process conditions (temperature, speed, and contact pressure), die surface modification (coating, texturing, and heat treatment), and workpiece surface improvement by coating and heat treatment $[6,7]$.

Recently, several studies have been presented to evaluate the influence of coating steel sheets on the performance of hot stamping dies [3, 4, 8-13]. 
In the work of Boher et al. [10] a high strength boron steel coated with Al-Si was hot stamped with dies made of three steels with different contents of carbon, chromium, vanadium, molybdenum, manganese, and silicon. The first die made of X50CrMoV5 steel is heat-treated and nitride-coated to present a fine and homogeneous martensite microstructure. The second material, nonnitrided 60CrMoTiV16 steel, presents good resilience and good wear resistance and a martensitic microstructure with fine and spherical precipitates and polyhedral large precipitates rich in titanium, tungsten, and silicon, which probably cause a significant fluctuation of hardness.

Finally, the third material called SG3, also nonnitrided, is fully martensitic with some fine and globular carbides rich in iron, tungsten, and silicon. From the results obtained with a deep-drawing process simulator (DDPS) they concluded that the most important wear mechanism was the material transfer caused by the adhesion of particles of the sheet coating during the hot sliding. The surface damage presented a rapid kinetics influenced by the hardness and particles shape and distribution of each die steel.

The modification of the surface texture by many manufacturing processes is being extensively studied [14-19] and the laser texturing (LT) is one of the most potentials to improve lubrication by lubricant retention and reduce wear and die damage to get products with high surface quality [20-26]. The topography of sliding surfaces can induce extra hydrodynamic pressure and increase the lubricant film stiffness, and the dimples or grooves can act as reservoirs for lubricants and trap debris to reduce abrasive wear [27].

Ibatan et al. [15] show the recent development on surface texturing to improve the tribological performance of bearing sliders. They comment that laser texturing is one of the most advanced surface texturing techniques to produce microdimple patterns by short processing times. Otherwise, LT involves focused pulsed laser, which may generate microdimple patterns surrounded by a solidified melt rim. Besides, material melting and vaporization create heat-affected zone areas on the solidified melt rim changing the local microstructures and mechanical properties demanding appropriate pulse energy and pulse frequency.

Ramesh et al. [16] also studied the influence of different textures on the lubrication testing different combinations of width, depth, and density of microgrooves produced by casting, tested in a high pressure tribometer (HPT) under mixed and hydrodynamic lubrication established by varying the normal load and the sliding speed. They concluded that, in some combinations, textured surfaces presented worst results than the nontextured tools. The best combination to reduce friction and wear was obtained with the groove depth equal to the film thickness, the grooves density around 20$30 \%$, and the groove width between 100 and $200 \mu \mathrm{m}$.

Geiger et al. [20] evaluated the influence of laser texturing on the lifetime of cold forging dies to minimize the wear caused by poor lubrication. They also studied the influence of two coatings on the textured surface: $\mathrm{TiN}$ and $\mathrm{TiN}+\mathrm{MoS}_{2}$. They concluded that textures with $\mathrm{TiN}+\mathrm{MoS}$ were the best to increase die lifetime because the dimples present in the textures retain lubricant, which is expelled during the process reducing the friction and minimizing abrasion.

Andersson et al. [21] analyzed the influence of laser texturing with some lubricant usually applied in the metal forming industry. The textured surfaces presented two densities of dimples and two ratios for the depth/diameter of the dimples. Three lubricants with different viscosities were applied. They concluded that laser texturing decreased significantly the friction and die wear, being the best combination of texture and lubrication that one with the lowest density of dimples, the largest ratio depth to diameter, and the most viscous lubricant.

In this work, we study the tribological effects of laser texturing the surface of hot stamping dies to evaluate the influence of the textures on the lubrication and wear by varying the diameter, the depth, and the density of the dimples and by evaluating the textures before and after the stamping tests by microhardness measurements, 3D surface topography, and scanning electron microscopy (SEM).

\section{Materials and Methods}

2.1. Preliminary Considerations. To define the conditions of laser texturing and lubrication, this work was based on some conclusions presented in the literature, which led to the hypotheses listed below considering the parameters shown in Figure 1.

As observed by Rapoport et al. [24], Ding et al. [27], and other researchers, the shape and the dimensions of the dimples are altered by the metallurgical transformations which occur during and after laser texturing and involve uncontrolled thermal expansion and contraction caused by repeated melting and solidification cycles which induce residual stresses. Crests (or bulges) may be formed, which, according to Ding et al. [27], are harmful to the formation of the tribofilm and can favor surfaces with galling.

Therefore, some hypotheses may be presented on the influence of the laser texturing parameters on the wear and lubrication:

(a) The increase in the number of dimples increases the retention of lubricant, so the density of dimples $(\gamma)$ must be as high as possible to retain more lubricant.

(b) The distance between two adjacent dimples $(\delta)$ must be as small as possible to guarantee forming a continuous film of lubricant with thickness $(t)$.

(c) Larger dimple diameters ( $d$ ) with small distance between dimples $(\delta)$ can build up a bulge with a crest; therefore the crest height $(H)$ must be limited to avoid metal-to-metal contact.

(d) To guarantee some lubricant to be expelled to the interface during sliding

(i) the diameter of the crest $(D)$ must be limited to avoid the excessive reduction of $\delta$ which could cause metal-to-metal contact;

(ii) the dimple depth $(h)$ must be less than the dimple diameter $(d)$; 

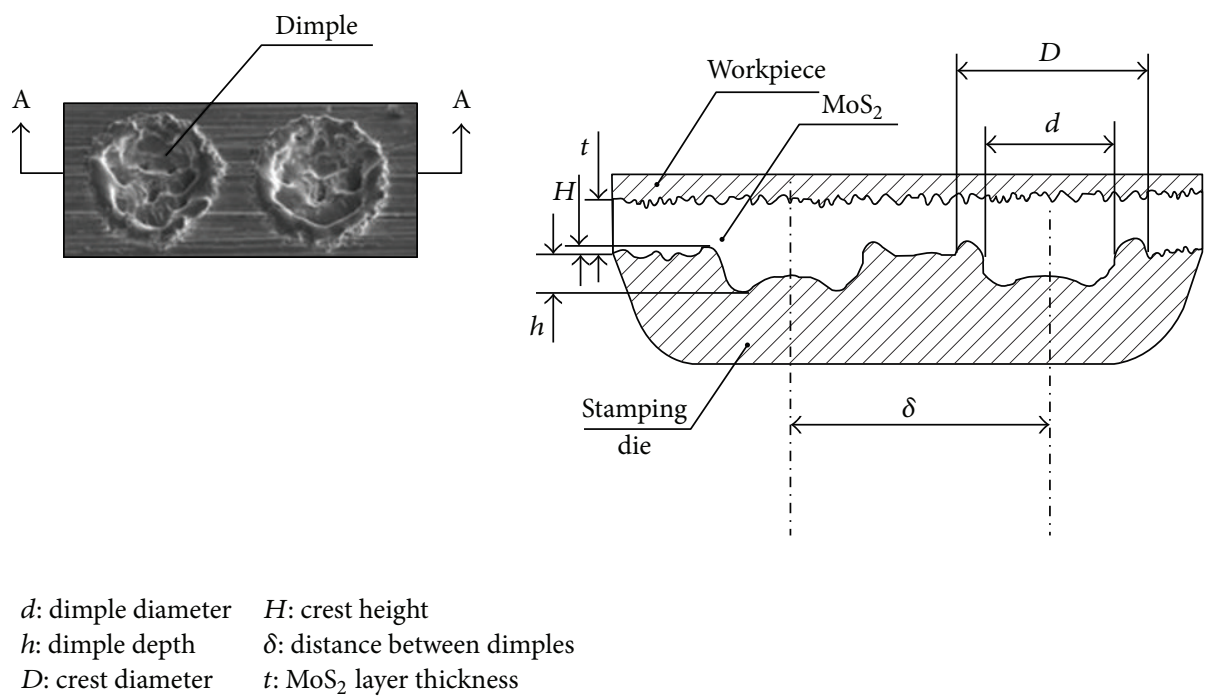

FIGURE 1: Parameters for the laser surface texturing of hot stamping dies.
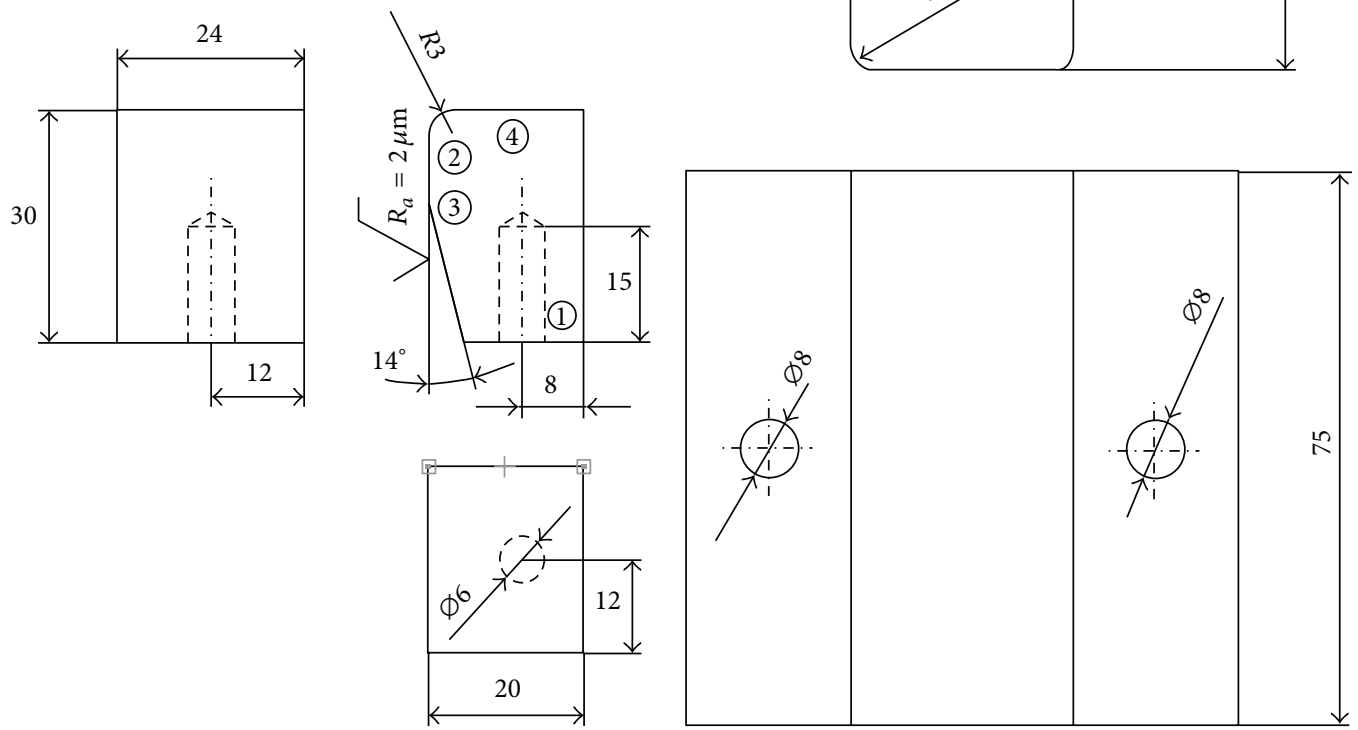

(a)

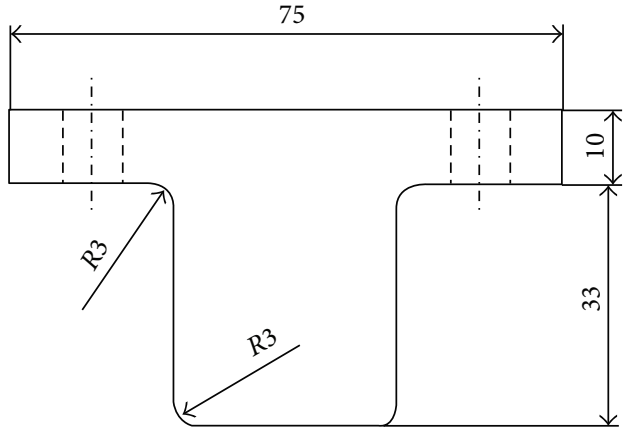

(b)

Figure 2: Dimensions (in mm) of the dies (a) and punch (b) used in the hot stamping tests.

(iii) the dimple depth $(h)$ added to the height of the crest $(H)$ must be less than the diameter of the crest $(D)$.

2.2. Numerical Simulation. To define the region of the dies to be laser textured, hot stamping of a steel part " $U$ " shaped was simulated using the software Forge 2008 based on the Finite Element Method (FEM) in which the wear of the dies is modeled by modified Archard's equations [28].

Figure 2 shows the tooling (punch and dies) designed for the hot stamping tests and Figure 3 shows the punch and dies with the sheet blank positioned and discretized for the 


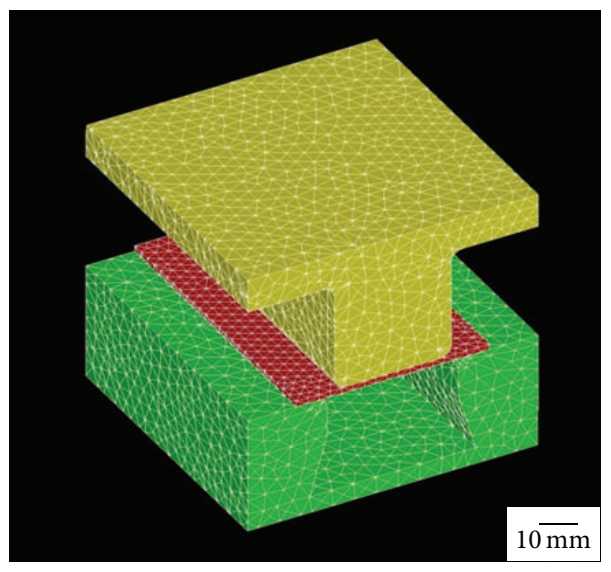

(a)

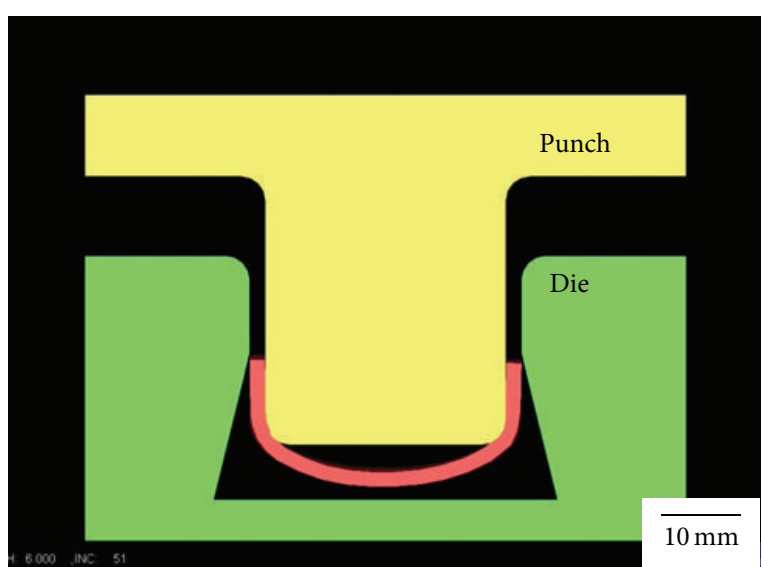

(b)

FIgURE 3: Numerical simulation-tooling and blank: before hot stamping (a) and after hot stamping (b).

TABLE 1: Inputs for the numerical simulation.

\begin{tabular}{lccc}
\hline & Material & Initial temperature & $\begin{array}{c}\text { Type and number } \\
\text { of finite elements }\end{array}$ \\
\hline Blank & Steel DIN 27MnCrB5-1.8 mm thick & $900^{\circ} \mathrm{C}$ & $\begin{array}{c}\text { Tetrahedral } \\
\text { finite elements } \\
14,623\end{array}$ \\
\hline Tooling & Steel AISI H13 & $25^{\circ} \mathrm{C}$ & $\begin{array}{c}\text { Triangular } \\
2,635\end{array}$ \\
\hline Process parameters & Press speed $10 \mathrm{~mm} / \mathrm{s}$ & Solid lubricant $\mathrm{MoS}_{2}$ & $\begin{array}{c}\text { Heat transfer coefficients and } \\
\text { materials properties [29] }\end{array}$ \\
\hline
\end{tabular}

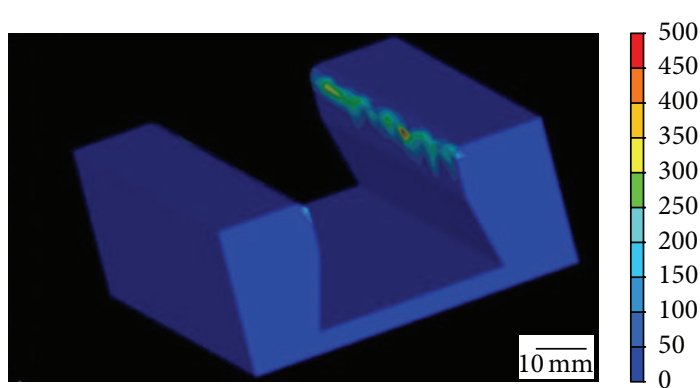

FIGURE 4: Die wear in MPa.mm-numerical results.

numerical test. Table 1 shows the conditions applied in the simulations.

As shown in Figure 4, the regions of the dies that presented the largest damage, in $\mathrm{MPa} \cdot \mathrm{mm}$, were the die radius and part of the vertical surface below. Boher et al. [10] obtained similar results confirming that those regions are interesting to analyze the influence of laser texturing.

2.3. Laser Texturing. The parameters to laser texturing the regions shown in Figure 4 were adopted considering the results obtained by Ramesh et al. [16] who concluded that the dimple depth $(h)$ should be near the film thickness in the interface die-blank. In this work, $h$ is assumed to be $30 \mu \mathrm{m}$ for two textures and $150 \mu \mathrm{m}$ for the other two to evaluate opposite conditions to supplying solid lubricant for the interface dieworkpiece.

Three distances between adjacent dimples (177, 266, 420, and $531 \mu \mathrm{m})$ and three dimple diameters (100, 150, and $300 \mu \mathrm{m}$ ) were chosen to evaluate the influence of dimples density equal to 10 or $25 \%$, as suggested by $\mathrm{Hu}$ et al. [25] who concluded that a dimple density of 15 to $25 \%$ is recommended to increase the amount of solid lubricant coating in the interface dies-workpiece and, consequently, to increase tool life.

All the surfaces were textured with a solid-state lamppumped Nd:YAG laser, operating at 1,064 nm wavelength with a power of $100 \mathrm{~W}$. The dimples dimensions were defined and controlled by the processing software available in the laser equipment.

Table 2 shows the conditions used to laser-texture each of the five textures analyzed in this work presented in Figure 5. All the dies were milled, quenched, and tempered to 52HRC, ground, and finally laser textured. A sixth die only ground $\left(R_{a}=2.0 \mu \mathrm{m}\right)$ was also tested and analyzed.

2.4. Hot Stamping Tests. The punch and the dies were assembled in a hydraulic press with nominal capacity of $300 \mathrm{kN}$ and work speed of $10 \mathrm{~mm} / \mathrm{s}$. Before each stamping test, the dies were cleaned and lubricated with solid $\mathrm{MoS}_{2}$.

The blank of DIN 27MnCrB5 steel (1.8 mm thick, $65 \mathrm{~mm}$ wide, and $82 \mathrm{~mm}$ long) was heated in an electric furnace at $900^{\circ} \mathrm{C}$ for 10 minutes and then transferred and hot stamped 


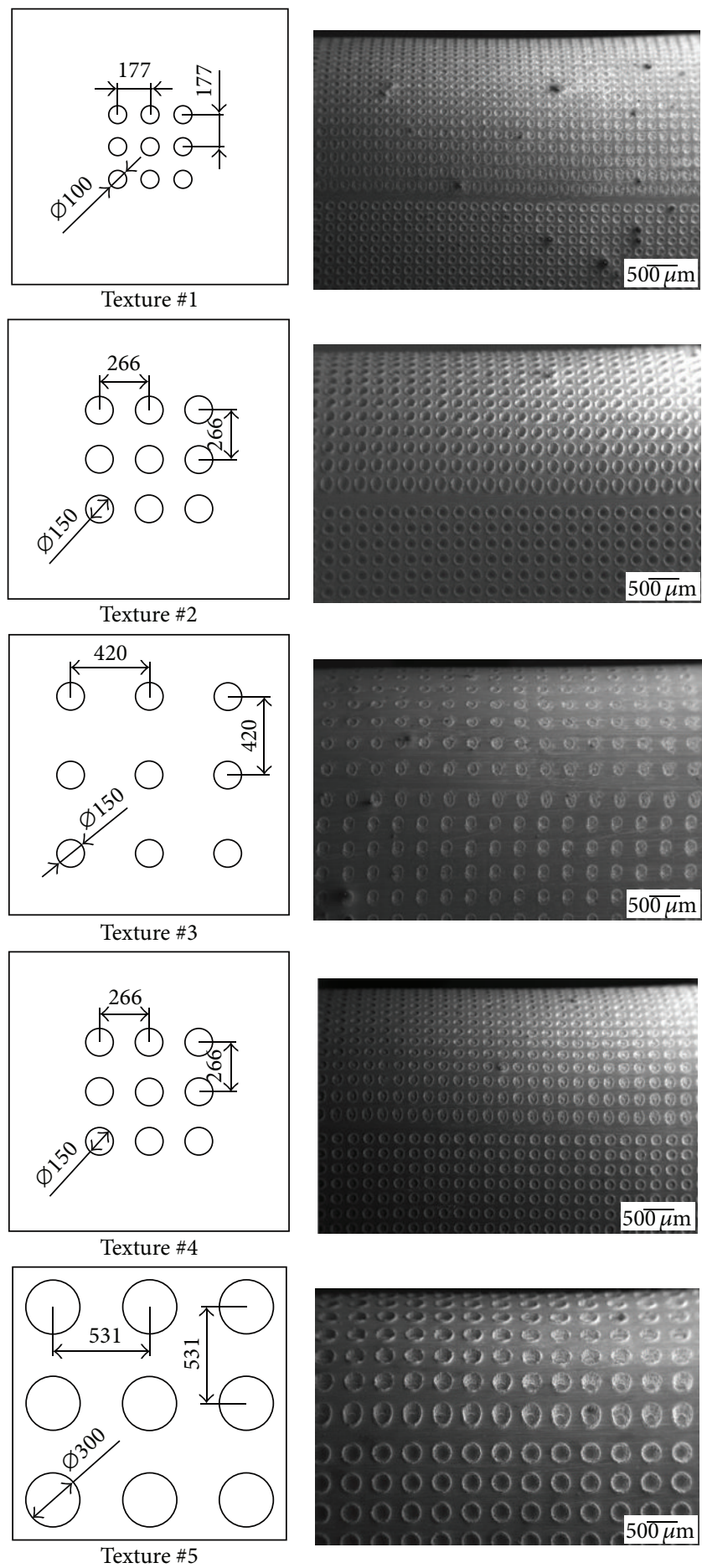

FIGURE 5: Sketches and SEM images at the die radius of the five textures before stamping tests.

in the press to form a "U" shaped part. Each texture was tested 100 times.

2.5. Characterization of the Laser Textured Dies. The textured surfaces of the dies were analyzed before and after the hot stamping tests to evaluate the surface topography, the microhardness, and the surface integrity. After hot stamping all the surfaces were cleaned with ethanol in ultrasound equipment before the analyses.

The surface topography was analyzed with the $3 \mathrm{D}$ profilometer WYKO NT100 from Veeco Instruments. The microhardness Vickers was measured three times in four positions (1) to (4) in Figure 2(a)) for each texture, with the microdurometer Buehler 2100 with a load of $10 \mathrm{~N}$. 
TABLE 2: Dimensions of the texture parameters shown in Figure 1.

\begin{tabular}{lcccc}
\hline Texture \# & $\begin{array}{c}\text { Dimple } \\
\text { depth }(h) \\
{[\mu \mathrm{m}]}\end{array}$ & $\begin{array}{c}\text { Distance } \\
(\delta) \\
{[\mu \mathrm{m}]}\end{array}$ & $\begin{array}{c}\text { Dimple } \\
\text { diameter }(d) \\
{[\mu \mathrm{m}]}\end{array}$ & $\begin{array}{c}\text { Density } \\
\pi \cdot(d / 2 \delta)^{2} \\
{[\%]}\end{array}$ \\
\hline 1 & 30 & 177 & 100 & 25 \\
2 & 150 & 266 & 150 & 25 \\
3 & 30 & 420 & 150 & 10 \\
4 & 30 & 266 & 150 & 25 \\
5 & 150 & 531 & 300 & 25 \\
\hline
\end{tabular}

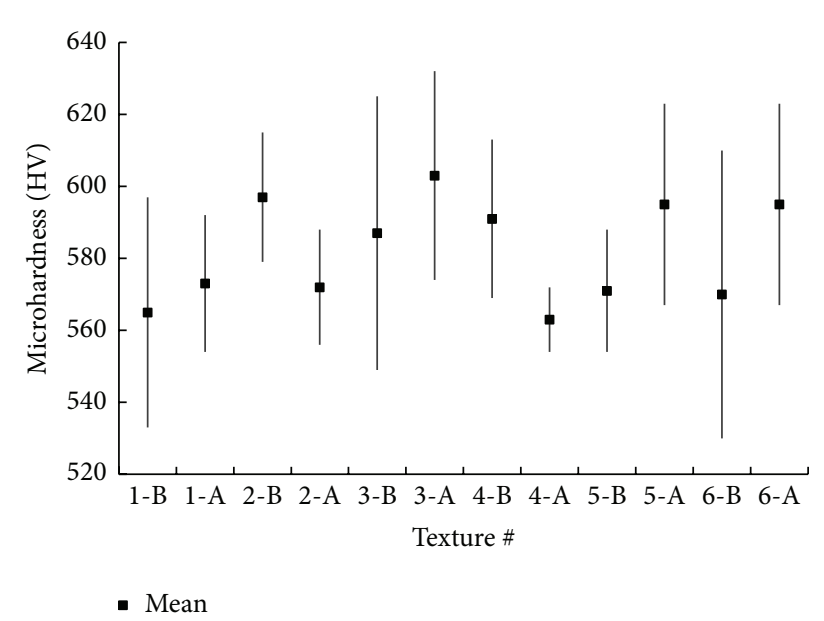

FIGURE 6: Microhardness Vickers measured in point (2) near the die radius for all textures before (B) and after (A) hot stamping tests: maximum, mean, and minimum values.

The scanning electron microscope Zeiss EVO MA15 was used to evaluate the surface integrity of the textured dies, respectively, before and after the stamping tests. The surfaces were also photographed with a digital camera Sony DSCW350.

\section{Results and Discussion}

3.1. Microhardness Vickers. Table 3 presents the results of microhardness Vickers for all textures measured before (B) and after (A) the hot stamping tests and Figure 6 shows the results for position (2) in Figure 2(a), near the die radius.

Comparing statistically the means and standard deviations for each point of the six textures before and after the stamping tests it may be concluded that there is not a significant difference, assuming a significance level $\alpha$ equal to 0.05 , and the same was observed when comparing the hardness at each point among the six textures, before or after the stamping tests. Therefore, the laser texturing and the stamping tests did not change the die hardness and, consequently, did not contribute to the wear of the textured surfaces.

3.2. Surface Topography. To evaluate how laser texturing affected the dimples geometry and dimensions, the diameters of six dimples were measured twice for each texture, totalizing twelve measurements. The same six dimples were taken to

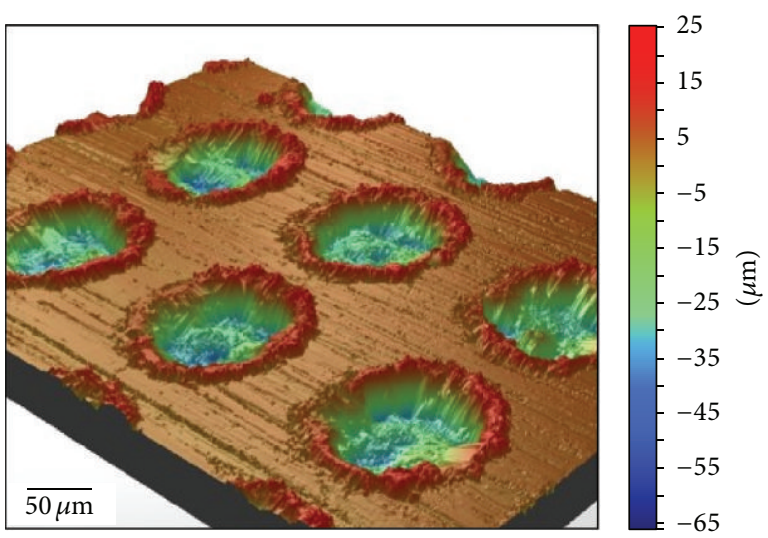

(a)

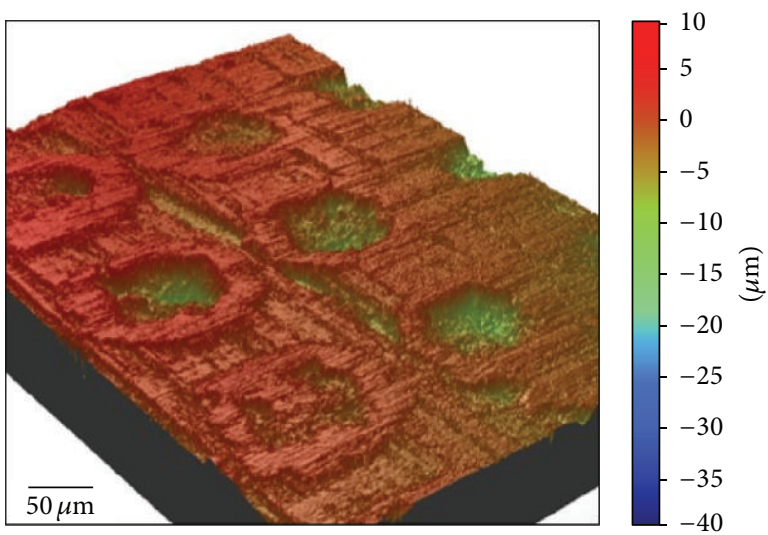

(b)

FIGURE 7: Surface topography-texture \#1, die radius: (a) before and (b) after the stamping tests.

measure three times the distance between adjacent dimples and dimples depth. Table 4 presents the results of the measurements from the profilometer analysis before the stamping tests.

The mean and dispersion of each dimension near the nominal values, except for the dimple depth of texture \#5 and the dimple diameter of textures \#3 and \#5, confirm that the conditions applied in the laser process allowed a controlled texturing in most of the conditions.

The dispersion of dimple diameter of texture \#3 kept the minimum dimple density near the nominal 10\% justifying the worst lubrication condition, as discussed in the analysis of the surface topography, and confirming the conclusions of Rapoport et al. [24].

Although texture \#5 presented a mean measured dimple depth smaller than the nominal and a mean dimple diameter larger than the nominal, the minimum dimple density was not reduced and the maximum density was increased to $43 \%$ that is near the optimum density (40 to 50\%) found by Rapoport et al. [24] and $43 \%$ found by $\mathrm{Hu}$ et al. [25]. Therefore, the highest dimple density of texture \#5 favored the trapping of lubricant and its availability to lubricate the interface, as will be discussed in the analysis of Figure 11(b).

Figures 7-12 show the results of the profilometer in the region of the die radius for the six surfaces before and after the stamping tests. 
TABLE 3: Microhardness Vickers of all textures before and after the hot stamping tests.

\begin{tabular}{|c|c|c|c|c|c|}
\hline \multirow{2}{*}{ Texture \# } & \multirow{2}{*}{ Position } & \multicolumn{2}{|c|}{ Before hot stamping tests } & \multicolumn{2}{|c|}{ After hot stamping tests } \\
\hline & & Mean [HV] & Standard deviation & Mean [HV] & Standard deviation \\
\hline \multirow{4}{*}{1} & 1 & 565 & 20 & 538 & 25 \\
\hline & 2 & 565 & 32 & 573 & 19 \\
\hline & 3 & 597 & 19 & 592 & 30 \\
\hline & 4 & 574 & 23 & 534 & 32 \\
\hline \multirow{4}{*}{2} & 1 & 486 & 40 & 590 & 32 \\
\hline & 2 & 597 & 18 & 572 & 16 \\
\hline & 3 & 534 & 35 & 576 & 4 \\
\hline & 4 & 525 & 23 & 568 & 23 \\
\hline \multirow{4}{*}{3} & 1 & 571 & 33 & 501 & 30 \\
\hline & 2 & 587 & 38 & 603 & 29 \\
\hline & 3 & 581 & 17 & 581 & 19 \\
\hline & 4 & 580 & 29 & 616 & 21 \\
\hline \multirow{4}{*}{4} & 1 & 607 & 19 & 563 & 12 \\
\hline & 2 & 591 & 22 & 563 & 9 \\
\hline & 3 & 584 & 51 & 565 & 29 \\
\hline & 4 & 530 & 20 & 569 & 32 \\
\hline \multirow{4}{*}{5} & 1 & 514 & 13 & 568 & 35 \\
\hline & 2 & 571 & 17 & 595 & 28 \\
\hline & 3 & 564 & 34 & 568 & 19 \\
\hline & 4 & 583 & 32 & 585 & 18 \\
\hline \multirow{4}{*}{ As grinded } & 1 & 548 & 26 & 592 & 28 \\
\hline & 2 & 570 & 40 & 595 & 28 \\
\hline & 3 & 564 & 25 & 568 & 19 \\
\hline & 4 & 568 & 27 & 585 & 35 \\
\hline
\end{tabular}

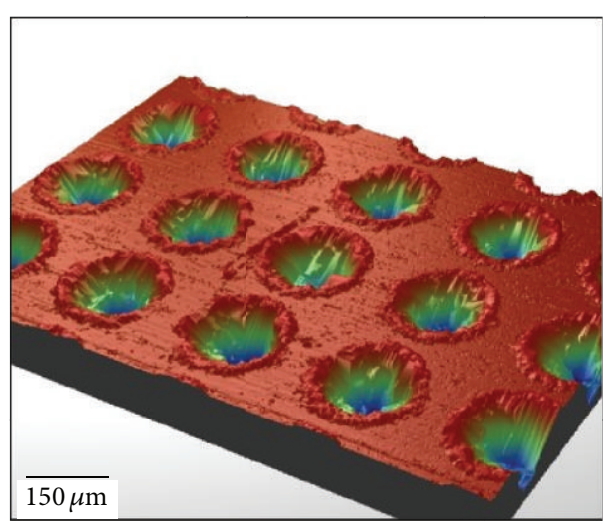

(a)

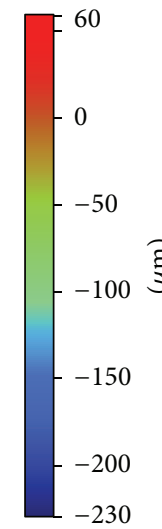

$-230$

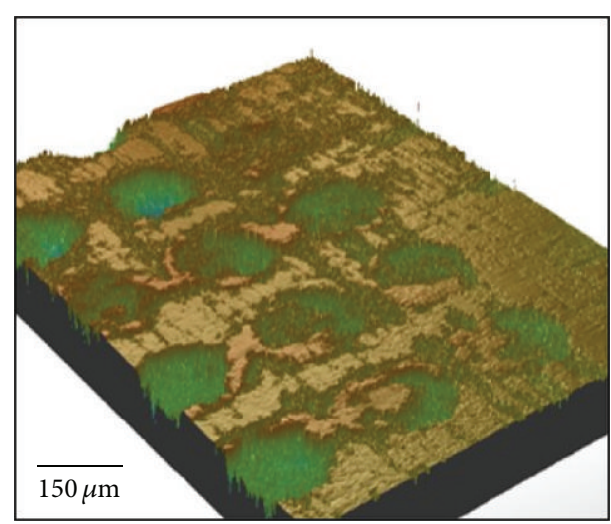

(b)

FIGURE 8: Surface topography-texture \#2, die radius: (a) before and (b) after the stamping tests.

Bulges are evident in textures \#1, \#2, and \#4 before the stamping tests, with the highest crests being observed in texture \#2 (Figure 8(a)), which presents the highest dimple depth, both nominal and measured (about $150 \mu \mathrm{m}$ ). Because texture \#2 presents smaller dimple diameter and spacing between adjacent dimples than texture \#5 (with the same nominal depth) and consequently should contain less lubricant and be more susceptive to galling, it could present a significant change of the surface as is actually observed in Figure 8(b). 


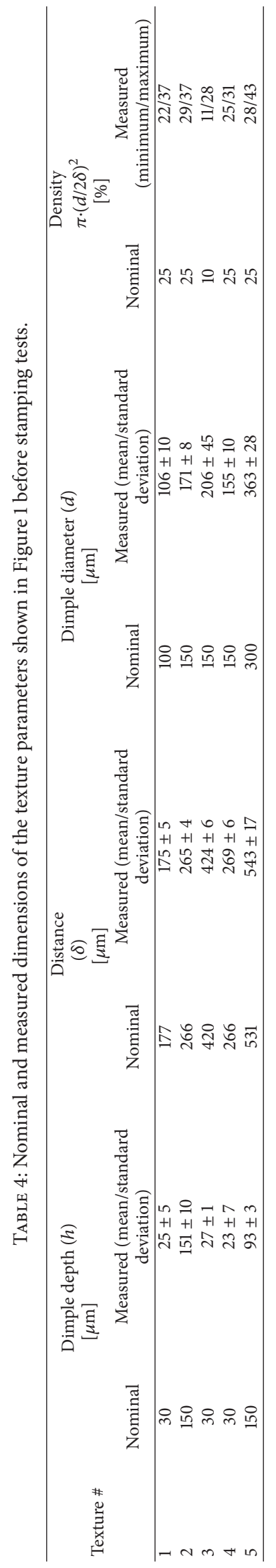




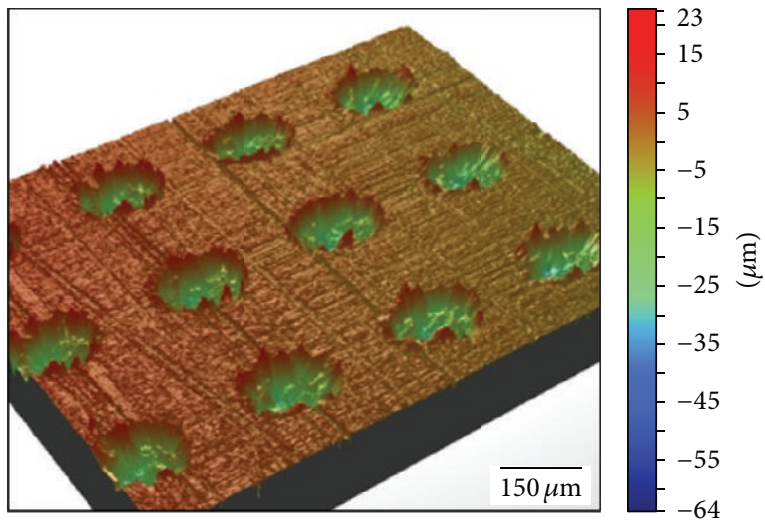

(a)

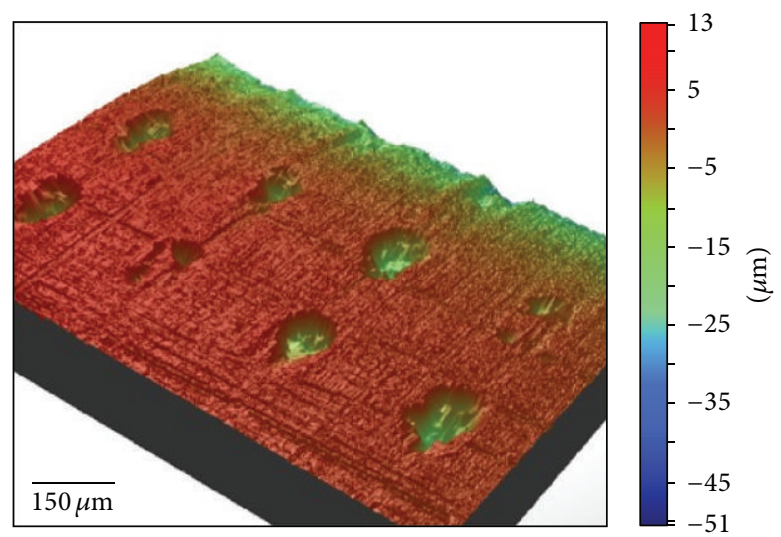

(b)

FIGURE 9: Surface topography-texture \#3, die radius: (a) before and (b) after the stamping tests.

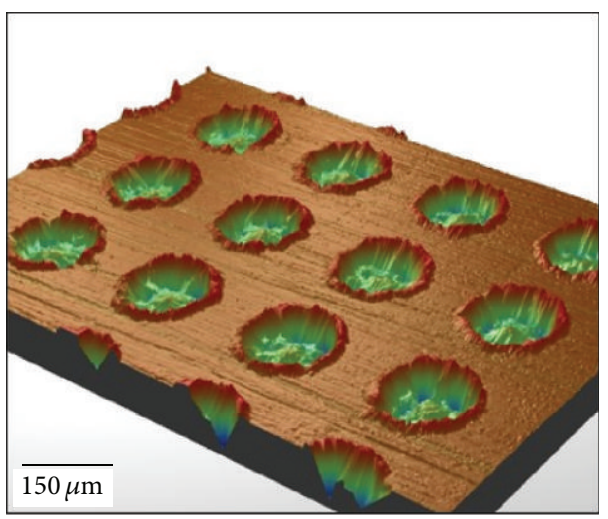

(a)

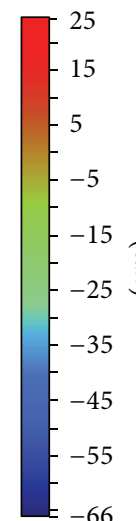

$-66$

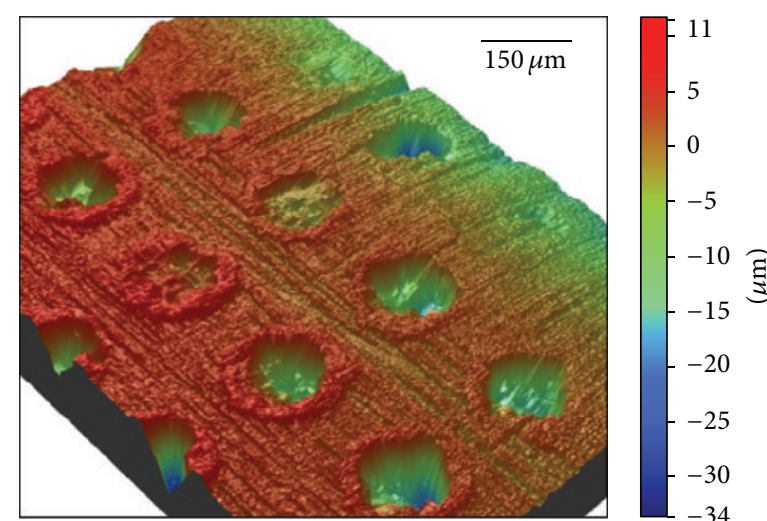

(b)

FIGURE 10: Surface topography_texture \#4, die radius: (a) before and (b) after the stamping tests.

Textures \#3 and \#5 presented few small crests, while textures \#1 and \#4 presented bulges with similar height and distribution. Textures \#1, \#3, and \#4 presented similar dimple depths before the stamping tests.

After the hot stamping tests, texture \#1 presented a significant change of topography, and dimple depth was significantly reduced (Figure 7(b)). The distance between dimples was also reduced by the approximation of bulges probably deformed by the metal-to-metal contact between the crests and the workpiece surface caused by the insufficient lubricant carried out from the small and shallow dimples.

Texture \#2 also experienced a significant change: the topography was completely modified, the dimple depth presented the highest reduction among the five textures, and the bulges were completely deformed flattening the surface (Figure 8(b)).

Before the stamping tests, texture \#3 (Figure 9(a)) had few bulges, the same dimple depth and dimple diameter of texture \#4, but had a spacing $60 \%$ larger than texture \#4 (Figure 10(a)). After the stamping tests, as observed in Figure 9(b), texture \#3 had most of the dimples deformed by wear during the stamping tests, and some practically disappeared, maybe because little lubricant was available in the shallow dimples and insufficient to lubricate the large surface among dimples with the lower density.

Otherwise, texture \#4 (Figure 10(b)) experienced a significant reduction in dimple depth, and the bulges were still present and deformed but did not decrease the spacing between the dimples.

Texture \#5, beyond presenting few bulges before stamping tests (Figure 11(a)), also presented high dimple diameter and spacing, which, respectively, prevented galling and increased the amount of lubricant trapped in the dimples, resulting after the hot stamping tests in a texture without crests and with preserved dimples since neither the depth nor the spacing was significantly reduced (Figure 11(b)).

The ground surface with average roughness of $2.0 \mu \mathrm{m}$ (Figure 12(a)) was significantly affected by the stamping tests (Figure 12(b)), the surface roughness was reduced, and parallel scratches were formed perpendicular to the original ones, probably by plowing caused by direct metalto-metal contact, confirming that smooth surfaces are not able to trap lubricant and avoid wear, as observed by other 


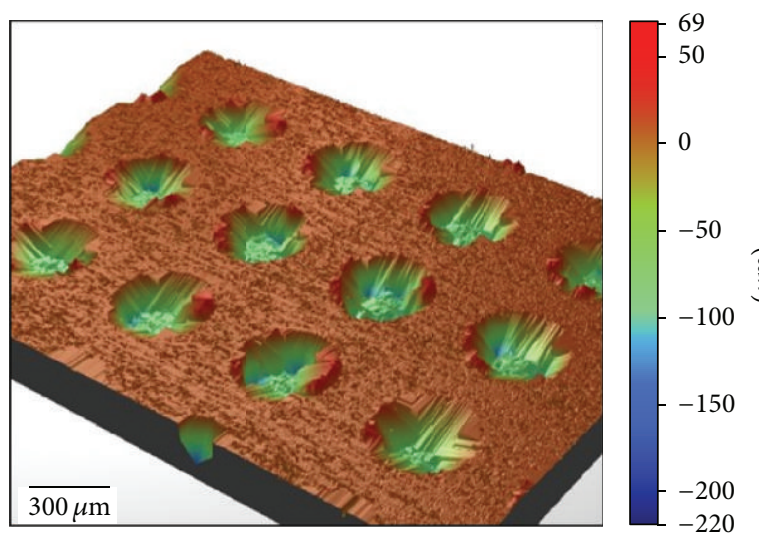

(a)

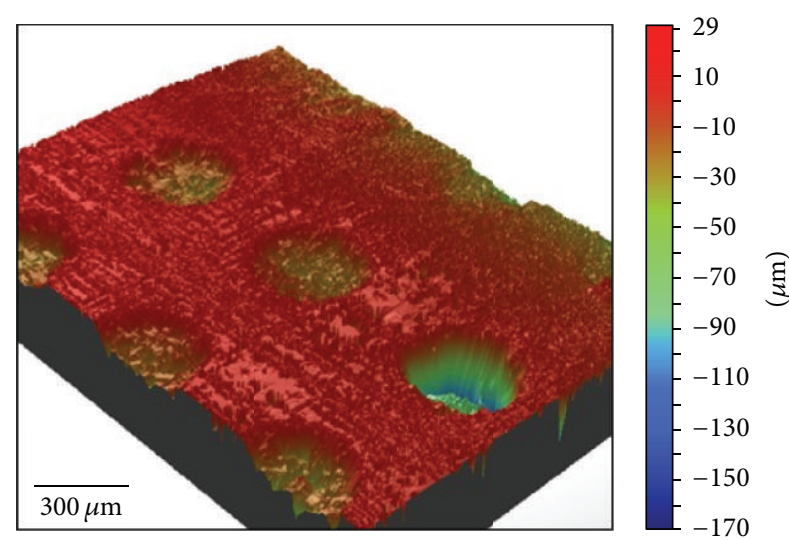

(b)

FIGURE 11: Surface topography_texture \#5, die radius: (a) before and (b) after the stamping tests.

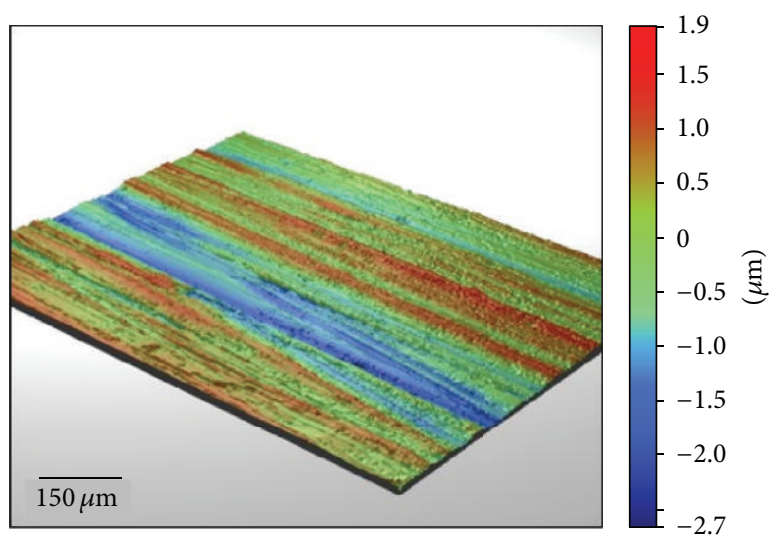

(a)

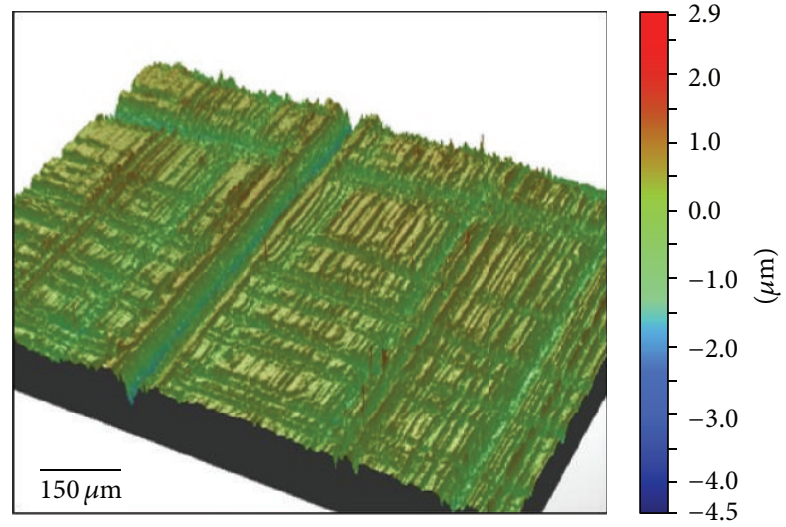

(b)

FiguRE 12: Surface topography—ground surface, die radius: (a) before and (b) after the stamping tests.

authors who compared textured and untextured surfaces $[16,27]$.

\subsection{Scanning Electron Microscopy. Figures 13-18 show the} SEM surfaces, in the region of the die radius, for the five laser textured dies and the ground surface before and after the stamping tests, with two magnifications: 200 and 700x.

SEM images are coherent to the results of the surface topography. Textures \#1, \#2, and \#3 (Figures 13(b), 14(b), and 15(b)) were completely modified by hot stamping tests, with bulges being almost completely deformed and flattened, probably by the wear by adhesion and galling caused by metal-to-metal contact and abrasion generated by oxides and other hard particles, as observed by Ghiotti et al. [8] and Wieland and Merklein [9] and by other researchers who also studied the tribology in hot stamping.

Most dimples of all textures are filled with particles of the solid lubricant or oxides from the workpiece at elevated test temperature, as can be observed in Figure 19, which shows particles in a dimple of texture \#5.

Otherwise, textures \#4 and \#5 (Figures 16(b) and 17(b)) presented the most preserved dimples after hot stamping tests, as observed and commented on before in the surface topography analysis, with the bulges being still present in texture \#4.

Texture \#5 practically presents the same dimples morphology after the stamping tests, except for the initial few bulges that were slightly flattened.

Finally, the images of the ground surface (Figure 18(b)) are also very similar to the surface topography (Figure 12(b)) with scratches perpendicular to the original ones, probably caused by abrasive wear, and apparently with a smoother surface than before the hot stamping tests.

\section{Conclusions}

The influence of dimples dimensions (diameter, depth, and spacing) on the performance of laser textured hot stamping 

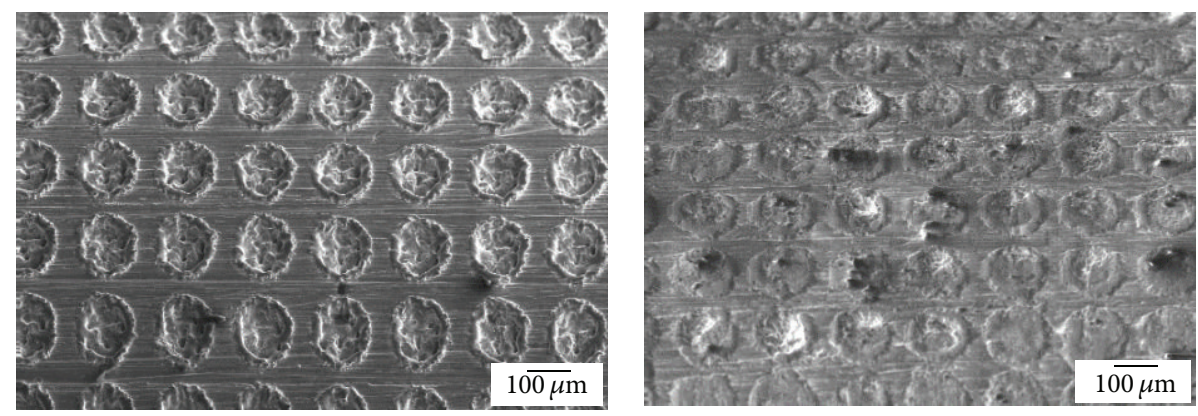

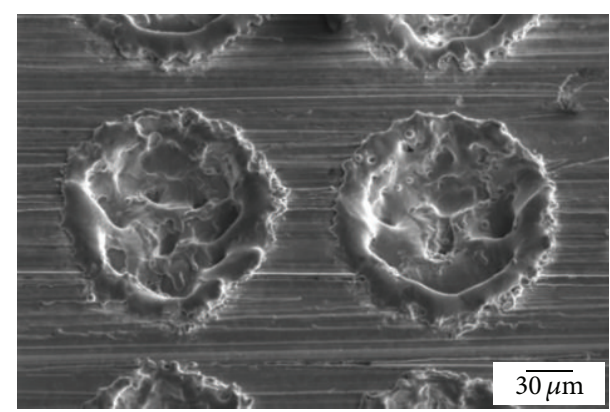

(a)

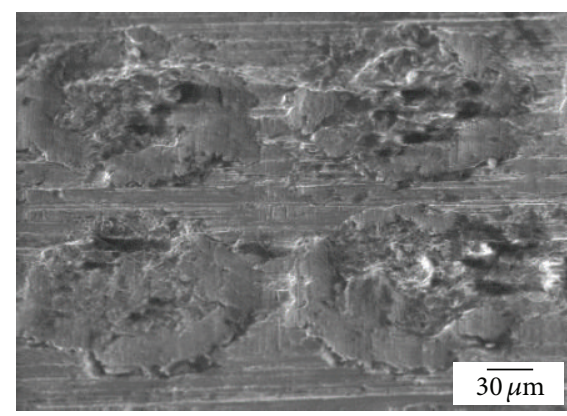

(b)

FIGURE 13: SEM images of die radius-texture \#1: (a) before and (b) after hot stamping tests.
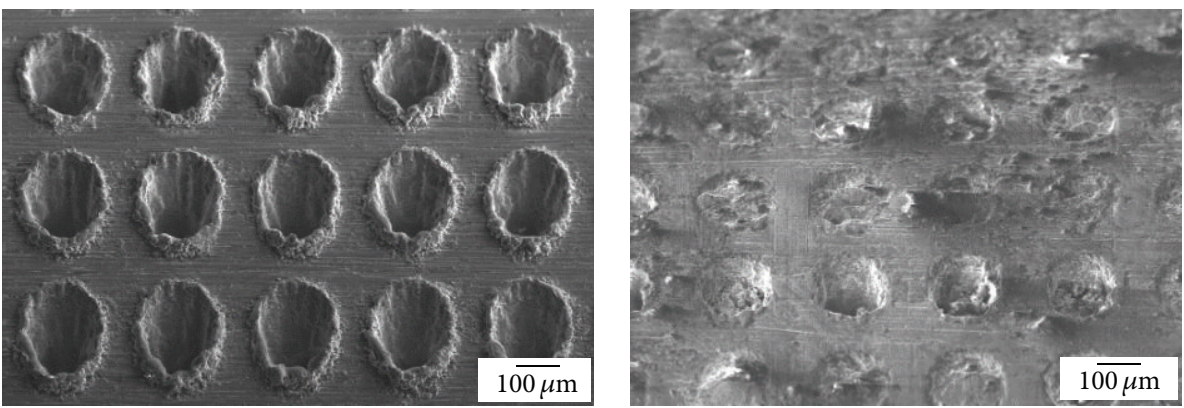

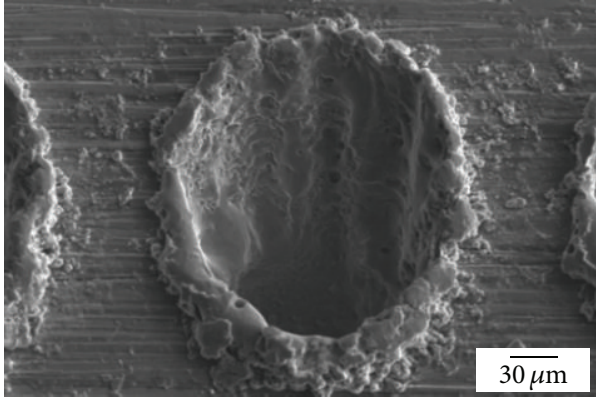

(a)

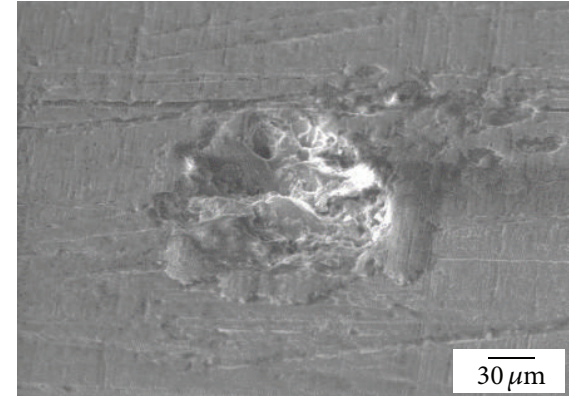

(b)

FIGURE 14: SEM images of die radius-texture \#2: (a) before and (b) after hot stamping tests.

dies has been studied, and the main conclusions are as follows:

(i) Laser texturing is a suitable process to improve the tribological performance of hot stamping dies, since all the textures evaluated in this work were better than the untextured surface to prevent metal-to-metal contact.

(ii) The processing conditions used to laser texturing gave good results in terms of dimple dimensions and spacing for most of the tested textures. 

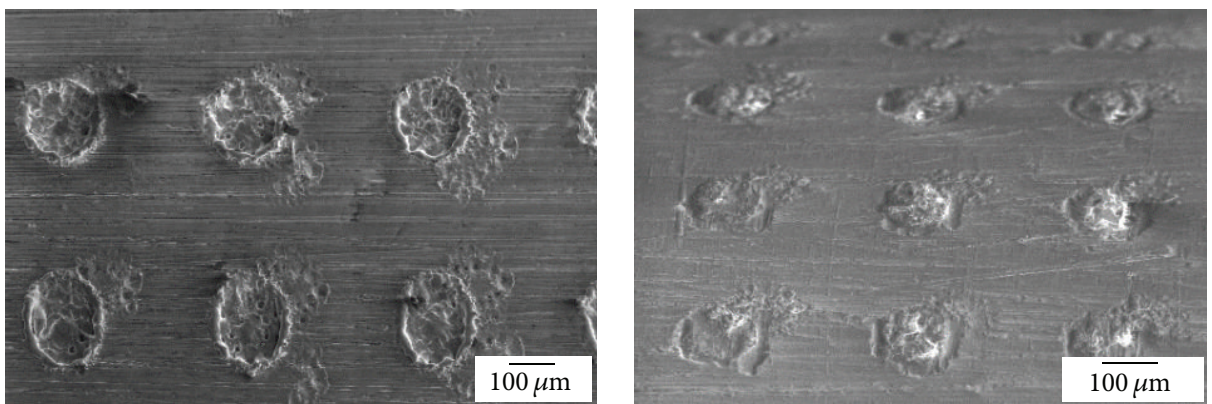

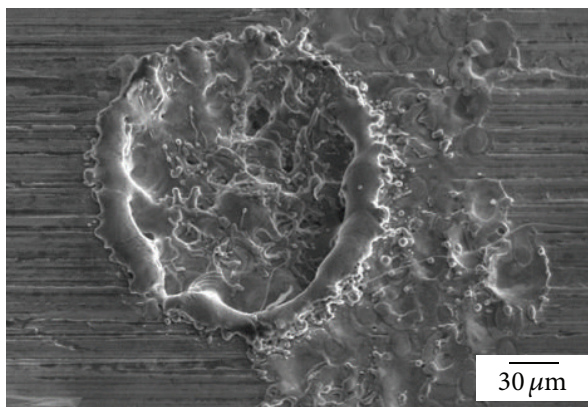

(a)

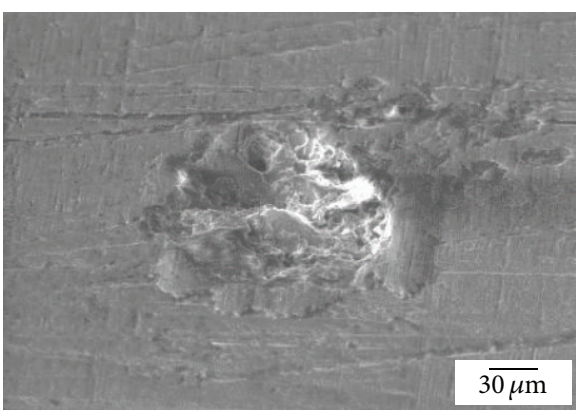

(b)

FIGURE 15: SEM images of die radius-texture \#3: (a) before and (b) after hot stamping tests.
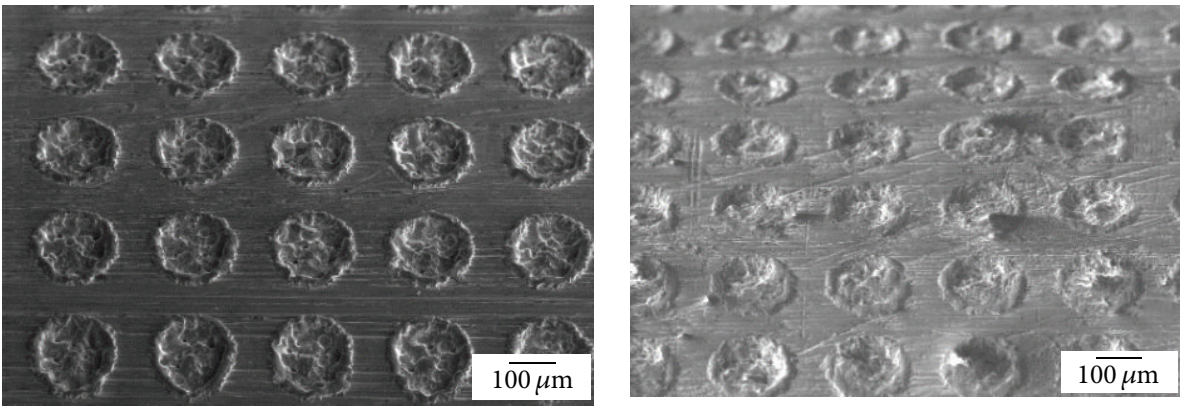

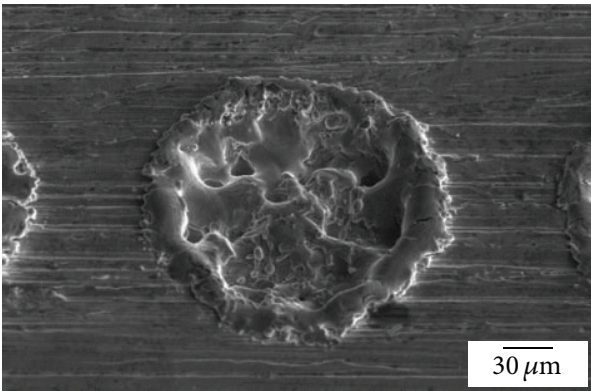

(a)

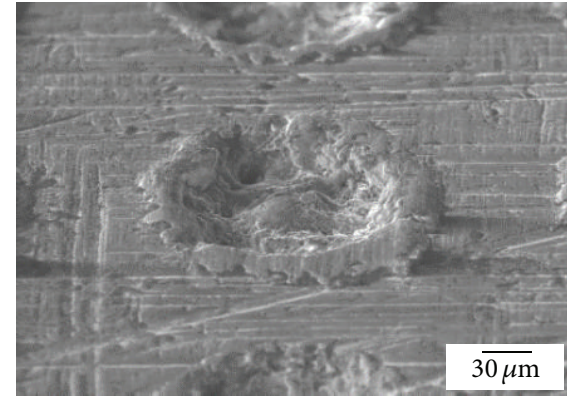

(b)

FIGURE 16: SEM images of die radius-texture \#4: (a) before and (b) after hot stamping tests.

(iii) Increasing the number of dimples increases the retention of lubricant, so the density of dimples must be as high as possible to retain more lubricant. However, the distance between two adjacent dimples cannot be too small to be interfered by the bulges built up during laser texturing and deformed in the hot stamping tests.

(iv) The dimple diameter must be the highest as possible with a high spacing to avoid metal-to-metal contact due to the high bulges. 

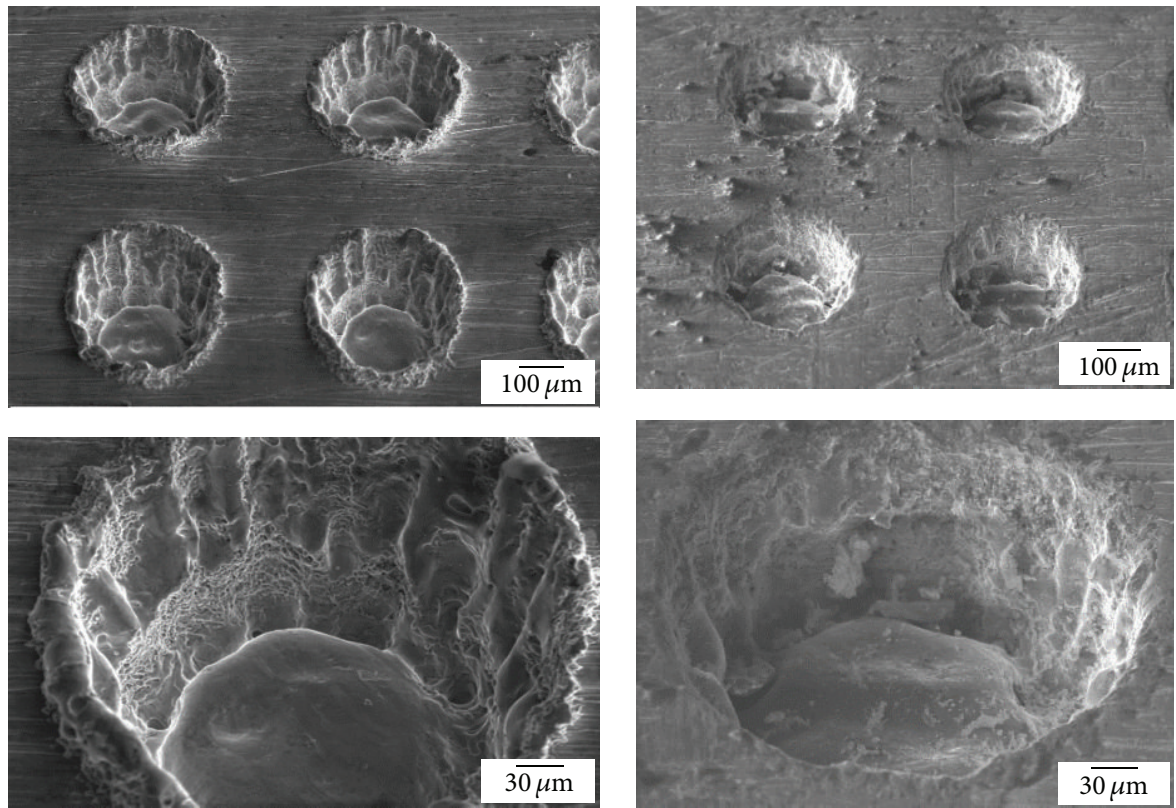

(a)

(b)

Figure 17: SEM images of die radius-texture \#5: (a) before and (b) after hot stamping tests.
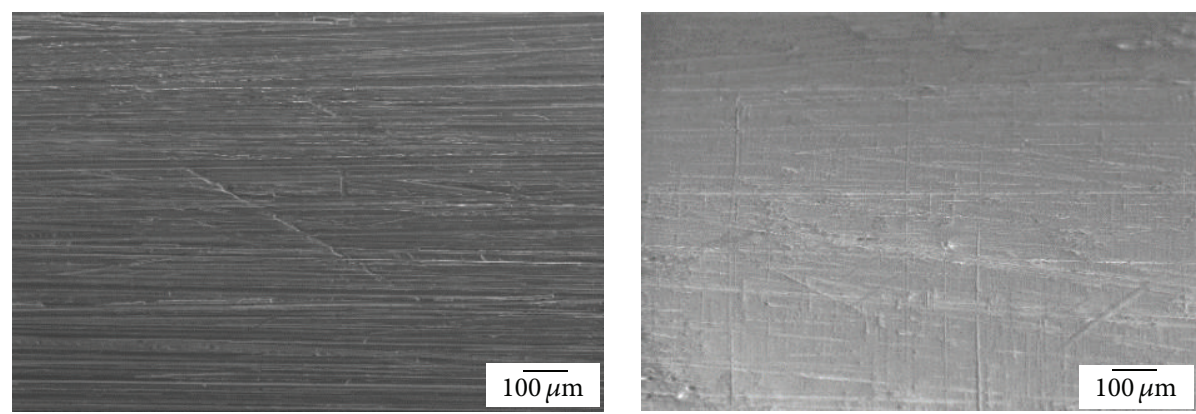

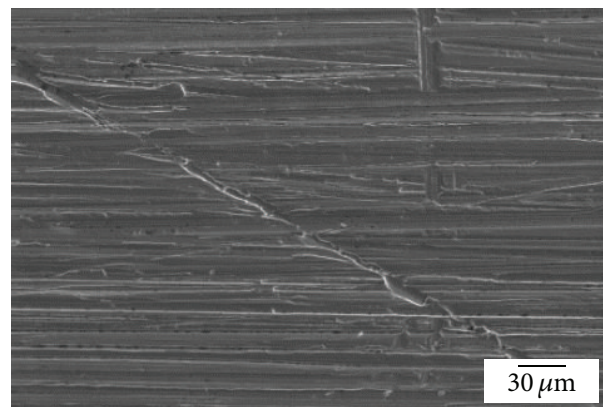

(a)

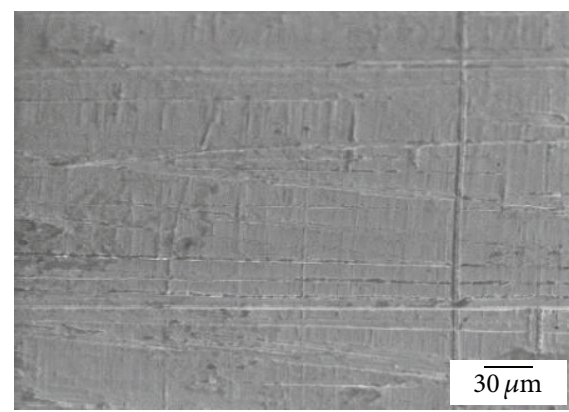

(b)

FIGURE 18: SEM images of die radius—ground surface: (a) before and (b) after hot stamping tests.

(v) Textures with the smallest dimples diameter, depth, and spacing presented the worst performance with the topography completely modified by adhesive and abrasive wear.

(vi) The best performance was obtained by the texture with the highest dimples density, near to $40 \%$, as concluded by other researchers, with the highest dimple diameter and spacing, and with a depth of one-quarter of the dimple diameter. The surface topography and dimples morphology were practically preserved after the stamping tests, except for the bulges that were slightly flattened. 


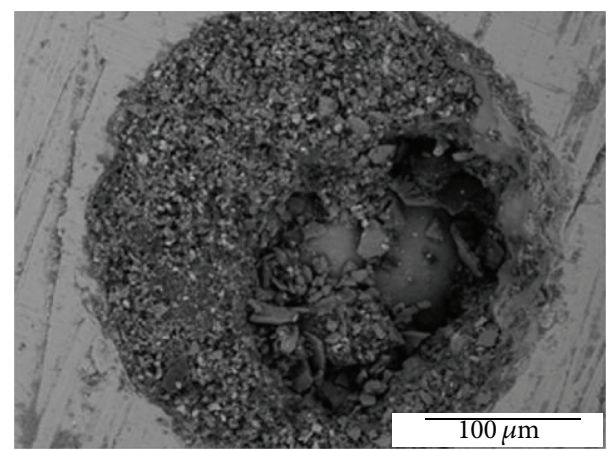

FIGURE 19: SEM image of particles inside a dimple on the die radius of texture \#5 after hot stamping tests.

\section{Competing Interests}

The authors declare that they have no competing interests.

\section{Acknowledgments}

The authors wish to thank FAPESP (Process 2011/12927-6) for the financial support to this work.

\section{References}

[1] H. Karbasian and A. E. Tekkaya, "A review on hot stamping," Journal of Materials Processing Technology, vol. 210, no. 15, pp. 2103-2118, 2010.

[2] A. Schubert, R. Neugebauer, D. Sylla, M. Avila, and M. Hackert, "Manufacturing of surface microstructures for improved tribological efficiency of powertrain components and forming tools," CIRP Journal of Manufacturing Science and Technology, vol. 4, no. 2, pp. 200-207, 2011.

[3] A. Ghiotti, S. Bruschi, and F. Borsetto, "Tribological characteristics of high strength steel sheets under hot stamping conditions," Journal of Materials Processing Technology, vol. 211, no. 11, pp. 1694-1700, 2011.

[4] M. R. Lovell and Z. Deng, "Characterization of interfacial friction in coated sheet steels: influence of stamping process parameters and wear mechanisms," Tribology International, vol. 35, no. 2, pp. 85-95, 2002.

[5] M. Merklein, J. M. Allwood, B.-A. Behrens et al., "Bulk forming of sheet metal," CIRP Annals-Manufacturing Technology, vol. 61, no. 2, pp. 725-745, 2012.

[6] X. Tian, Y. Zhang, and J. Li, "Investigation on tribological behavior of advanced high strength steels: influence of hot stamping process parameters," Tribology Letters, vol. 45, no. 3, pp. 489-495, 2012.

[7] F. Findik, "Latest progress on tribological properties of industrial materials," Materials and Design, vol. 57, pp. 218-244, 2014.

[8] A. Ghiotti, F. Sgarabotto, and S. Bruschi, "A novel approach to wear testing in hot stamping of high strength boron steel sheets," Wear, vol. 302, no. 1-2, pp. 1319-1326, 2013.

[9] M. Wieland and M. Merklein, "Wear behavior of uncoated and coated tools under complex loading conditions," Tribology in Industry, vol. 34, no. 1, pp. 11-17, 2012.

[10] C. Boher, S. Le Roux, L. Penazzi, and C. Dessain, "Experimental investigation of the tribological behavior and wear mechanisms of tool steel grades in hot stamping of a high-strength boron steel," Wear, vol. 294-295, pp. 286-295, 2012.

[11] S. Hernandez, J. Hardell, H. Winkelmann, M. R. Ripoll, and B. Prakash, "Influence of temperature on abrasive wear of boron steel and hot forming tool steels," Wear, vol. 338-339, pp. 27-35, 2015.

[12] A. Ghiotti, S. Bruschi, F. Sgarabotto, and P. F. Bariani, "Tribological performances of $\mathrm{Zn}$-based coating in direct hot stamping," Tribology International, vol. 78, pp. 142-151, 2014.

[13] L. Pelcastre, J. Hardell, and B. Prakash, "Galling mechanisms during interaction of tool steel and Al-Si coated ultra-high strength steel at elevated temperature," Tribology International, vol. 67, pp. 263-271, 2013.

[14] D. J. Wentink, D. Matthews, N. M. Appelman, and E. M. Toose, "A generic model for surface texture development, wear and roughness transfer in skin pass rolling," Wear, vol. 328-329, pp. 167-176, 2015.

[15] T. Ibatan, M. S. Uddin, and M. A. K. Chowdhury, "Recent development on surface texturing in enhancing tribological performance of bearing sliders," Surface and Coatings Technology, vol. 272, pp. 102-120, 2015.

[16] A. Ramesh, W. Akram, S. P. Mishra, A. H. Cannon, A. A. Polycarpou, and W. P. King, "Friction characteristics of microtextured surfaces under mixed and hydrodynamic lubrication," Tribology International, vol. 57, pp. 170-176, 2013.

[17] J. G. Parreira, C. A. Gallo, and H. L. Costa, "New advances on maskless electrochemical texturing (MECT) for tribological purposes," Surface and Coatings Technology, vol. 212, pp. 1-13, 2012.

[18] M. L. Magri, A. E. Diniz, and S. T. Button, "Influence of surface topography on the wear of hot forging dies," International Journal of Advanced Manufacturing Technology, vol. 65, no. 14, pp. 459-471, 2013.

[19] D. Jucius, A. Guobiene, and V. Grigaliūnasa, "Surface texturing of polytetrafluoroethylene by hot embossing," Applied Surface Science, vol. 256, no. 7, pp. 2164-2169, 2010.

[20] M. Geiger, U. Popp, and U. Engel, "Excimer laser micro texturing of cold forging tool surfaces-influence on tool life," CIRP Annals-Manufacturing Technology, vol. 51, no. 1, pp. 231234, 2002.

[21] P. Andersson, J. Koskinen, S. Varjus et al., "Microlubrication effect by laser-textured steel surfaces," Wear, vol. 262, no. 3-4, pp. 369-379, 2007.

[22] T. Hu, L. Hu, and Q. Ding, "Effective solution for the tribological problems of Ti-6Al-4V: combination of laser surface texturing and solid lubricant film," Surface and Coatings Technology, vol. 206, no. 24, pp. 5060-5066, 2012.

[23] J. Li, D. Xiong, H. Wu, Y. Zhang, and Y. Qin, “Tribological properties of laser surface texturing and molybdenizing duplextreated stainless steel at elevated temperatures," Surface and Coatings Technology, vol. 228, supplement 1, pp. S219-S223, 2013.

[24] L. Rapoport, A. Moshkovich, V. Perfilyev et al., "Friction and wear of $\mathrm{MoS}_{2}$ films on laser textured steel surfaces," Surface and Coatings Technology, vol. 202, no. 14, pp. 3332-3340, 2008.

[25] T. Hu, Y. Zhang, and L. Hu, “Tribological investigation of $\mathrm{MoS}_{2}$ coatings deposited on the laser textured surface," Wear, vol. 278279, pp. 77-82, 2012.

[26] A. Rosenkranz, L. Reinert, C. Gachot, and F. Mücklich, "Alignment and wear debris effects between laser-patterned steel surfaces under dry sliding conditions," Wear, vol. 318, no. 1-2, pp. 49-61, 2014. 
[27] Q. Ding, L. Wang, and L. Hu, “Tribology optimization by laser surface texturing: from bulk materials to surface coatings," in Laser Surface Engineering, chapter 16, pp. 405-422, Woodhead Publishing, 2015.

[28] J. F. Archard, "Contact and rubbing of flat surfaces," Journal of Applied Physics, vol. 24, no. 8, pp. 981-988, 1953.

[29] M. H. F. Batalha and S. T. Button, "Hot formability of DIN 27MnCrB5 steel sheets under controlled thinning," Journal of Materials Processing Technology, vol. 228, pp. 98-105, 2016. 


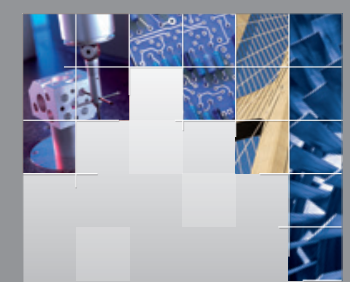

\section{Enfincering}
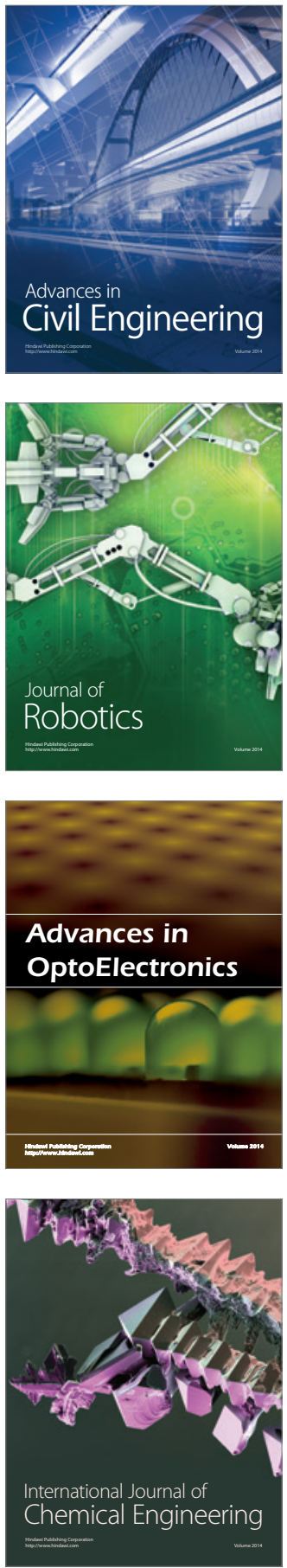

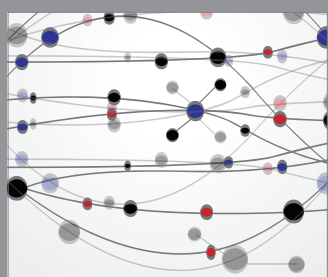

The Scientific World Journal

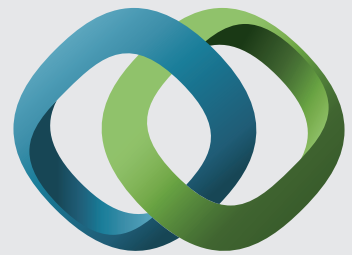

\section{Hindawi}

Submit your manuscripts at

http://www.hindawi.com
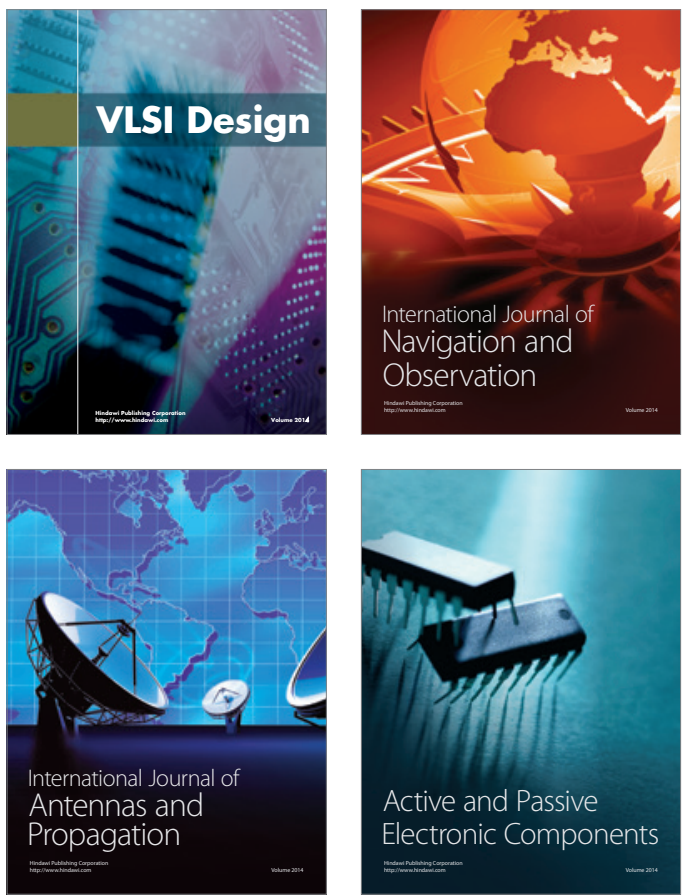
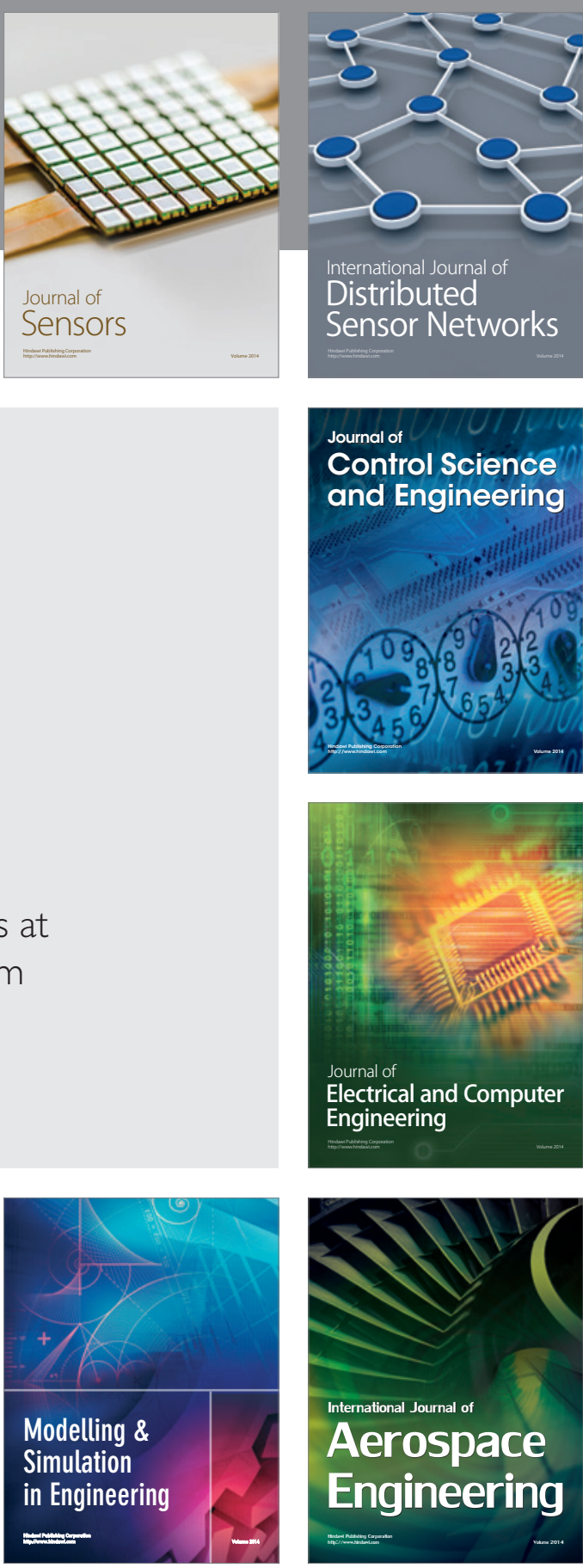

International Journal of

Distributed

Sensor Networks

Journal of

Control Science

and Engineering
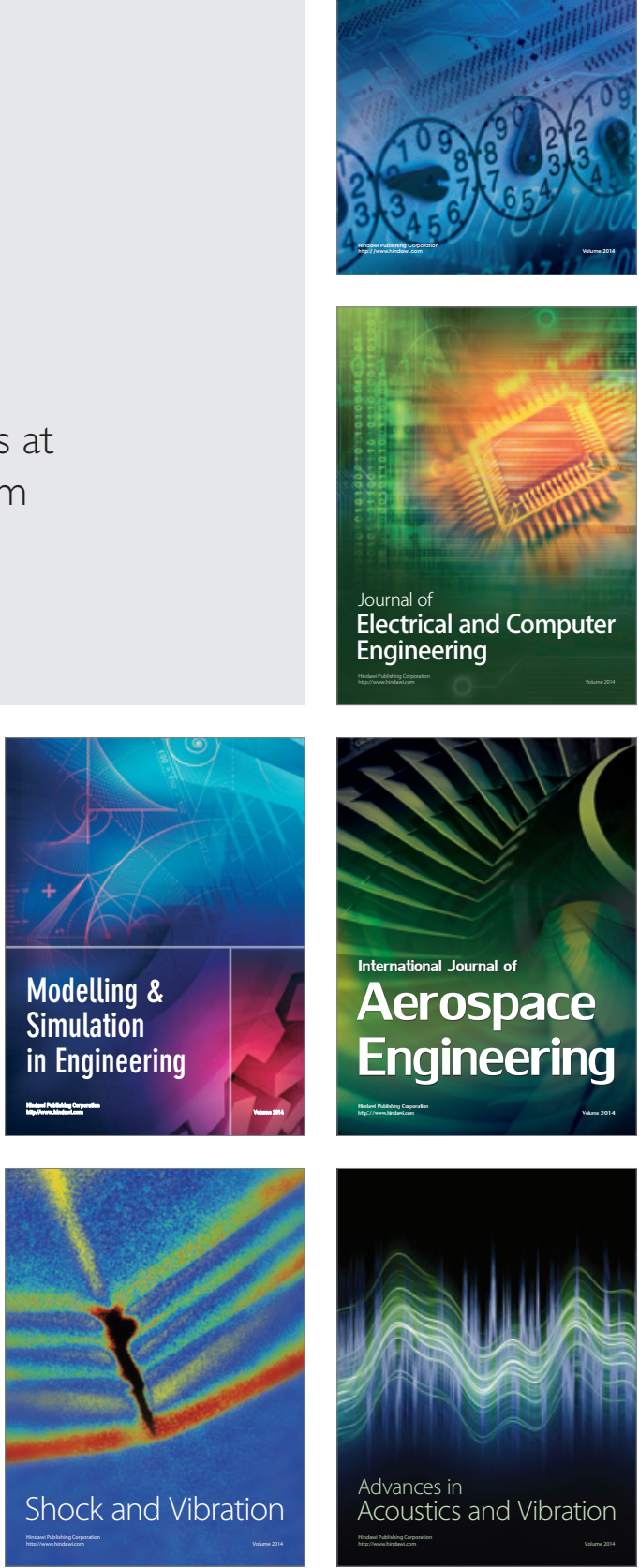